\title{
A Review of the Material Characteristics, Antifreeze Mechanisms, and Applications of Cryoprotectants (CPAs)
}

\author{
Xiangjian Liu, ${ }^{1}$ Yuxin Pan, ${ }^{1}$ Fenglin Liu, ${ }^{1}$ Yongju He, ${ }^{2}$ Qubo Zhu, ${ }^{1}$ Zhaolin Liu, ${ }^{3}$ \\ Xuehui Zhan $\left(\mathbb{D},{ }^{4}\right.$ and Songwen Tan $(\mathbb{1})^{1}$ \\ ${ }^{1}$ Xiangya School of Pharmaceutical Sciences, Central South University, Changsha 410013, China \\ ${ }^{2}$ School of Materials Science and Engineering, Central South University, Changsha 410013, China \\ ${ }^{3}$ Department of Dermatology, Xinhua People's Hospital, Loudi 417600, China \\ ${ }^{4}$ School of Physics and Electronic Science, Changsha University of Science and Technology, Changsha 410114, China \\ Correspondence should be addressed to Xuehui Zhan; zhanxueh@163.com and Songwen Tan; songwen.tan@csu.edu.cn
}

Received 11 March 2021; Revised 16 March 2021; Accepted 13 April 2021; Published 3 May 2021

Academic Editor: Antonio Vassallo

Copyright (C) 2021 Xiangjian Liu et al. This is an open access article distributed under the Creative Commons Attribution License, which permits unrestricted use, distribution, and reproduction in any medium, provided the original work is properly cited.

Cryopreservation has been a key technology in medical science, food preservation, and many other fields. In a freezing process, the formation of ice crystals may cause significant damage to the frozen samples. In order to reduce the damage, many cryoprotectants (CPAs) have been developed and added in cryopreservation processes for reduced ice volume, decreased ice size, proper ice shaping, and cell protection. According to the material characteristics, the CPAs are either impermeable (i.e., antifreeze protein, polyampholytes, and polyvinyl alcohol) or permeable (i.e., dimethyl sulfoxide, proline, and glycerol) to cell membranes. The typical CPAs are introduced in this work with their material characteristics, antifreeze mechanisms, and applications. Antifreeze mechanisms for different CPAs involve molecular adsorption on the ice surface, hydrogen bonding to ice, bending the ice surface, lowering the freezing point, inhibiting ice recrystallization, protecting cell membranes, reducing dehydration of cells, and breaking hydrogen bonds among ice crystals to reduce the size of ice crystals. In practice, different CPAs can be used together with their cryopreservation properties functioning synergetically. This study reviews the recent applications of CPAs in food, biology and medicine, and agriculture. Future works for CPAs are suggested in improving efficiency, revealing mechanisms, broadening application, and finding new CPAs.

\section{Introduction}

In recent years, the demand for cryopreservation has been increasingly high in food, biology, medicine, and many other fields [1-3]. Since the rate of deterioration is reduced at low temperatures, the shelf lives of products, namely, the lifecycles of organisms, can be prolonged by freezing [4]. Long-term cryopreservation of cells and tissues also needs to maintain their bioactivity [5]. However, organisms are easily damaged during freezing with the following two types of injury: osmotic injury and mechanical injury, as shown in Figure 1. Osmotic injury is caused by the freezing of the extracellular solution, leading to increases in the concentrations of the solutes. Subsequently, the cells are damaged by osmotic dehydration. Mechanical injury refers to the puncture damage of cells by sharp ice crystals [6]. During thawing, small ice crystals disap- pear while large ones grow, namely, ice recrystallization, which is consistent with Ostwald ripening. Large ice crystals formed by ice recrystallization can cause severe, even fatal, mechanical injury to cells [7]. These two kinds of injuries restrict the development of cryopreservation.

In order to restrict osmotic injury and mechanical injury, researchers are committed to developing cryoprotectants (CPAs) for cryopreservation processes. CPAs are a class of agents that can prevent or reduce damage from freezing and/or thawing. The earliest CPAs came from the special proteins, namely, antifreeze proteins (AFPs), in polar fishes that allowed them to survive in the extreme cold conditions of subzero temperatures [8]. Later, different AFPs have been found in insects $[9,10]$, bacteria [11], plants [12], and so forth. In recent years with revelation of the antifreeze mechanisms, some antifreeze proteins have also been called ice- 




Ice Water (19) Cell

Figure 1: Schematic diagram of osmotic injury and mechanical injury to cells.

binding proteins (IBPs) or ice structure proteins (ISPs) in line with their molecular interactions with ice. For the convenience of expression, this article still refers to these proteins as AFPs.

According to the material characteristics, the CPAs are either impermeable or permeable to cell membranes. Permeable CPAs are mostly small molecules, such as dimethyl sulfoxide (DMSO) [13] and proline [14], which can penetrate into cells and prevent cells from low-temperature injuries during cryopreservation. Impermeable CPAs include AFPs, polyvinyl alcohol (PVA) [15], polyampholytes [16], graphene oxide [17], and so forth. These types of CPAs work outside the cells, structuring the ice shapes to lower the lowtemperature damage. Although the mechanism of permeable and impermeable CPAs is different, both the two types of CPAs have good cryopreservation ability and may be jointly used in many cases.

AFPs have been widely used in many fields but still can hardly achieve perfect cryopreservation [18]. More CPAs have been found, modified or synthesized in recent decades to improve cryopreservation. In this paper, the representative and popular CPAs of these two types (permeable and impermeable) are selected. Their properties, functions, and mechanisms are introduced in detail in the following sections (briefly listed in Table 1). The work also presents the methods to determine if a substance has a cryoprotective effect, the applications of the CPAs, and the methods to improve the activity of CPAs. Based on current findings and discussion, future directions in cryopreservation are proposed.

\section{Impermeable CPAs}

2.1. Antifreeze Protein (AFP). AFPs can significantly reduce the freezing point of a solution, whereas most AFPs have no effect on the melting point. The phenomenon of keeping the freezing point below the melting point, namely, thermal hysteresis (TH), is achieved by adsorption of AFP molecules on the ice-forming surface curvatures [18]. Under the Kelvin effect, thermodynamically, it is more difficult for $\mathrm{H}_{2} \mathrm{O}$ molecules to bind to a curved surface than a flat one, thus leading to thermal hysteresis [20]. With thermal hysteresis, organisms will not freeze at temperatures slightly below $0^{\circ} \mathrm{C}$, where freezing damage is avoided. Another property of AFP is ice recrystallization inhibition (IRI). AFP can inhibit the forma- tion of large ice crystals by recrystallization of small ice crystals, where the large crystals can puncture cells and are lethal to organisms.

The mechanism of ice recrystallization is related to Ostwald ripening, where the diffusion of free $\mathrm{H}_{2} \mathrm{O}$ molecules between ice crystals plays a key role in ice recrystallization. AFP adsorbed on the ice surface can restrain the $\mathrm{H}_{2} \mathrm{O}$ diffusion, thus inhibiting ice recrystallization [21]. IRI increases the freezing tolerance of organisms, where only small ice crystals exist. Some reports have claimed that many types of macromolecules have IRI activity, whereas only AFPs have the TH property [22]. When AFP has been added to a sample, the formed ice crystals are very small due to the IRI activity. These small ice crystals, however, can integrate to form large aggregation and fuse if the curved parts of two ice crystals get too close to each other. Since the system becomes less stable with the growth of curved ice, the ice crystals may eventually become a network structure to make the system stable [23].

There are three proposed mechanisms for the AFP adsorption on ice surfaces. The first hypothesis is the formation of hydrogen bonding [17], where the hydroxyls on the AFP first attach to the ice surface forming several hydrogen bonds. Subsequently, the hydroxyls occupy the sites of oxygen atoms on the ice leading to the formation of more hydrogen bonds. The second hypothesis is with regard to the hydrophobic effect. The confined water molecules around hydrophobic areas of AFP can diffuse away from the hydrophobic areas, driving AFP-binding to ice with entropy increasing. The third mechanism is called anchored clathrate hypothesis, where there will be ice-like clathrate waters around the ice-binding site (IBS) of AFP [24]. The ice-like clathrate waters have similar physical properties like the quasiliquid water layers on the ice surface. The ice-like clathrate layer and the quasiliquid layer would merge during freezing, binding AFP to ice [20].

The antifreeze property of AFP is also related to the cell culture and the location (intracellular or extracellular) of AFP. Tomas et al. [25] studied the location effect of AFP on cell suspension and monolayer cryopreservation. The result showed that in cell suspension cryopreservation, neither intracellular nor extracellular AFP had a significant effect on the cell recovery. In the study of monolayer cryopreservation, intracellular AFP increased the cell recovery at a low 
TABLE 1: Structure, mechanism, and applications of typical CPAs.

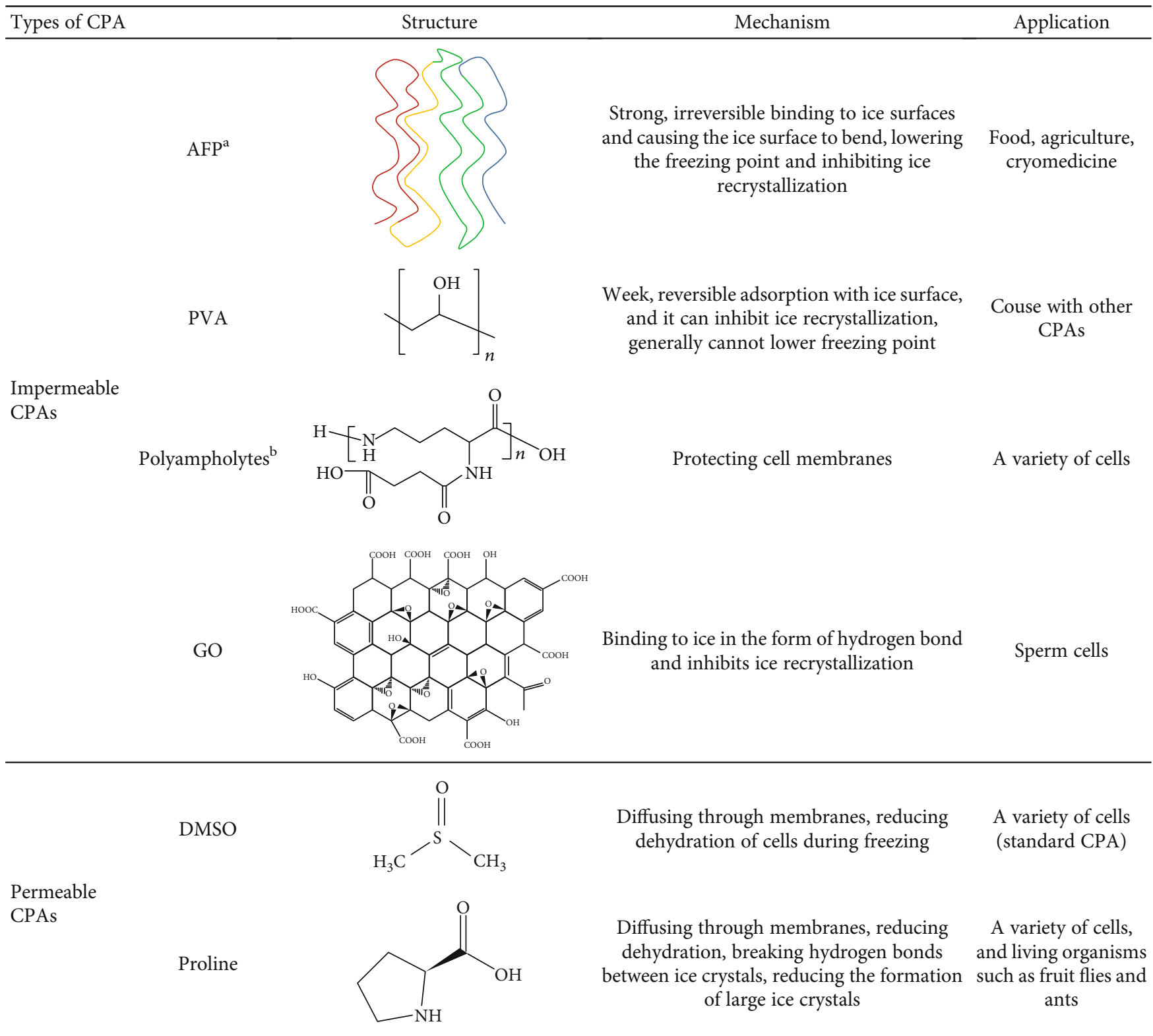

${ }^{a}$ The simple schematic of snow flea antifreeze protein structure [10]. ${ }^{\mathrm{b}}$ The structure refers to COOH-PLL [19].

DMSO concentration while extracellular AFP increased the cell recovery at a high DMSO concentration.

Just as every coin has two sides, AFP has some disadvantages. Some AFPs have been reported with cytotoxicity to human embryonic liver ( $2 \mathrm{mg} / \mathrm{mL}$ of AFP) and embryonic kidney cells $(0.63 \mathrm{mg} / \mathrm{mL}$ of AFP) $[18,26]$. The problem may be solved using artificially synthesized AFPs instead of natural ones to avoid potential immunogenicity and toxicity concerns. In addition, when high concentrations of AFP are used, the shape of the extracellular ice will change from dendritic to sharp bipyramidal, puncturing cell membranes [27].

2.2. Polyvinyl Alcohol (PVA). PVA has been proven to be an effective macromolecular CPA, mainly through the IRI cryoprotective effect. Contrary to the strong, irreversible adsorp- tion of AFP, the interaction between PVA and ice is weak and reversible. The PVA in solution that adsorbed on ice may be less than $9 \%$ [28]. When the concentration of PVA is only $5 \times 10^{-7} \mathrm{~mol} / \mathrm{L}$, it can still effectively inhibit ice recrystallization [29]. The IRI activity of PVA is proportional to the concentration and molecular weight. PVA with a very small molecular weight has almost no IRI activity. Vail et al. [30] proved that the critical degree of polymerization of PVA with IRI activity was 12 . If PVA shows IRI activity with the degree of polymerization lower than 12 , the reason can be related to its high polymer dispersity index (PDI), where the sample contained a small amount of highly polymerized PVA. In another study, when the PVA with a degree of polymerization of 10 is terminated with catechol, the star-shaped polymer can be formed under the trigger of $\mathrm{Fe}^{3+}$ where the IRI 
activity switches on [31]. The complete structure of PVA is crucial to its IRI activity [32]. The IRI activity decreases by adding hydrophobic or hydrophilic groups to PVA because the added groups on the PVA chain destroy its precise hydroxyl arrangement for ice binding. Even if the arrangement of hydroxyls is not significantly affected, simply increasing the hydrophobicity also results in less activity. It is inconsistent with the prediction that the hydrophobicity improves the IRI activity [33]. Within a certain range, the IRI activity of PVA is positively correlated with $\mathrm{pH}$ of the solution but does not rely on the types of positive and negative ions [28]. Although the reason for this phenomenon has not been studied, the $\mathrm{pH}$ must affect the physiochemical characteristics of hydrogen bonds [34] and ice surface [35].

The IRI activity of PVA owes to its precisely arranged hydroxyls, which can be paired with the ice surface. So PVA can be adsorbed on the ice surface through hydrogen bonds. In contrast, although polyols have multiple hydroxyls, their IRI activity is very weak since there is no precise hydroxyl structure for ice binding [36]. Regarding this finding, some polymers have been synthesized with similar structures (arrangement of hydroxyls) to PVA, such as the linear polyglycerol [28].

2.3. Polyampholyte. Polyampholytes are emerging CPAs with balanced anion and cation side chains [37]. Matsumura and Hyon [19] polymerized $\varepsilon$-poly-L-lysine (PLL) with succinic anhydride to produce polymers with different carboxylation ratios (COOH-PLL). They found that $\mathrm{COOH}-\mathrm{PLL}$ with a ratio of carboxylation at 0.65 and a concentration of $7.5 \%$ wt had the optimal cryoprotective activity. By using it at the optimal conditions, the viability of the postthaw cells exceeded 90\% (better than using 10\% DMSO). Subsequently, $\mathrm{COOH}-\mathrm{PLL}$ became a research hotspot in cryopreservation. Fujikawa et al. [38] found that COOH-PLL was not toxic to cells, and thawed cells could continue to survive in $\mathrm{COOH}$ PLL. To compare, when DMSO is used in cryopreservation, it must be removed immediately after thawing to prevent its toxicity from damaging cells. As shown in Table 2, $\mathrm{COOH}-\mathrm{PLL}$ has been applied for cryopreservation of human mesenchymal stem cells (hBMSC) [39], islet cells [40], bull semen [41], human induced pluripotent stem (iPS) cells [42], and so forth. COOH-PLL can work solely or in combination with other CPAs.

Finding new polyampholytes as CPAs is also a research hotspot. The poly(methyl vinyl ether-alt-maleic anhydride) has been polymerized with dimethylaminoethanol to obtain polyampholyte [5]. The carboxyl is the anionic group, and the dimethylamino is the cationic group. This polyampholyte can increase the cell recovery of monolayer cryopreservation to $88 \%$ and can also greatly reduce the amount of DMSO used in suspension cryopreservation. In order to further explain the structure-activity relationship of polyampholytes, Stubbs et al. [37] used 2-(dimethylamino)ethyl methacrylate (MDEAMA) and methacrylic acid (MMA) as anion and cation components. 120 polymers were obtained by highthroughput RAFT polymerization. Their cryopreservation ability was measured by the red blood cell recovery after freezing-thawing processes. The results showed that the poly- mer containing $4 \%$ ethyl methacrylate (HEMA) had the highest cell recovery, while the polymer containing $10 \%$ cyclohexyl methacrylate (CyMA) had the lowest cell recovery. It showed that simply increasing the hydrophobicity of the polymer cannot improve the cryoprotective activity. In contrast, the strong hydrophobic effect of the cyclohexyl methacrylate resulted in the weakest cryoprotective activity.

Unlike PVA and AFP, most polyampholytes have very weak IRI activity. At present, the mechanism of action of polyampholytes has not been fully understood. But it is generally believed that polyampholytes can stabilize cell membranes, thereby preventing cells from freezing-induced damage [43].

2.4. Graphene Oxide (GO). Graphene oxide (GO) is a classic two-dimensional material, and it has recently been found to be suitable for cryopreservation [17]. After adding GO to the sample for freezing, the rate of ice crystal growth decreased significantly. There are many precisely arranged hydroxyls on GO. These hydroxyls can be adsorbed on the ice surface through hydrogen bonds, bending the ice surface and inhibiting the growth of ice. This is similar to the mechanism of AFP. GO also has good biocompatibility, which can improve the activity of postthaw sperm cells. Some classic materials may be tried for cryopreservation if they contain a lot of hydroxyls.

\section{Permeable CPAs}

3.1. Dimethyl Sulfoxide (DMSO). DMSO is a classic permeable CPA and is the widely used CPA for cell cryopreservation [16]. DMSO, discovered in 1959, was found to have good permeability to living cells, and it could protect frozen red blood cells and bull sperm cells [44]. Subsequently, Ashwoodsmith [45] found that DMSO could reduce the freezing damage of mouse bone marrow cells at $-79^{\circ} \mathrm{C}$. The postthaw cell ability to synthesize proteins and liposomes retained 50-60\%. Stiff et al. [46] combined DMSO with hydroxyethyl starch (HES) in cryopreservation, which could directly freeze cells at $-80^{\circ} \mathrm{C}$ without the need for programmed cooling.

DMSO can penetrate into cells and partially dehydrate them, thereby reducing the damage to cells caused by ice. Although DMSO is an effective CPA for most cells, it is an organic solvent with inherent toxicity that can cause apoptosis, developmental disorders, and impaired enzyme functions $[47,48]$ and may induce abnormal differentiation of stem cells [49]. After thawing, DMSO also needs to be quickly washed and removed. This process may cause osmotic shocks that significantly damage cells [50]. In addition, DMSO is not suitable for cell monolayer cryopreservation [25], since monolayer cells can be typically injured during the freezing [51]. Therefore, many researchers are looking for CPAs that can reduce or replace the use of DMSO in cryopreservation.

3.2. Proline. Proline is an endogenous amino acid. Studies have shown that proline is related to the freezing tolerance of some plants. For example, genetically modified tobacco with high proline productivity has improved freezing 
TABLE 2: Cryopreservation of various cells using COOH-PLL.

\begin{tabular}{lcccccc}
\hline Types of cells & $\begin{array}{c}\text { Optimum } \\
\text { concentration (\%wt) }\end{array}$ & $\begin{array}{c}\text { Ratio of } \\
\text { carboxylation }\end{array}$ & $\begin{array}{c}\text { Viability } \\
(\%)\end{array}$ & $\begin{array}{c}\text { Viability of control group } \\
(10 \% \text { DMSO) }(\%)\end{array}$ & Combination & Reference \\
\hline L929 cell & 7.5 & 0.65 & $>95$ & $\sim 80$ & None & {$[19]$} \\
$\begin{array}{l}\text { Bovine } \\
\text { fibroblast cells }\end{array}$ & 5 & 0.65 & 96.5 & $\sim 85$ & None & {$[38]$} \\
$\begin{array}{l}\text { Bovine } \\
\text { cumulus cells }\end{array}$ & 20 & 0.65 & 95.3 & $\sim 90$ & None & {$[38]$} \\
hBMSC & 7.5 & 0.65 & $>95$ & $\sim 85$ & None & {$[39]$} \\
Islet cells & 20 & None & 74 & No report & $30 \%$ wt ethylene glycol & {$[40]$} \\
Bull semen & $0.75(v / v)$ & None & $\sim 80$ & No report & $5 \% v / v$ glycerol & {$[41]$} \\
iPS cell & 10 & 0.65 & 61.6 & No report & $\begin{array}{c}\text { 0.75 M sucrose, } 6.5 \mathrm{M} \\
\text { ethylene glycol }\end{array}$ & {$[42]$} \\
\hline
\end{tabular}

tolerance to cold environments [52]. Withers and King [53] have discovered that proline can protect Zea mays L cells showing a higher cell recovery after thawing, compared to glycerol and DMSO. The mechanism is related to the molecular diffusion through cell membrane, where proline enters into cells to counteract the osmotic injury caused by dehydration during the freezing process. In addition, proline can break hydrogen bonds between ice structures to inhibit their growth, reducing mechanical injury to cells from large ice crystals [14]. The cryopreservation ability of proline for various cells is shown in Table 3. Compared with DMSO, proline is an endogenous, nontoxic compound with good biocompatibility and may be suitable for cryopreservation of food, cells, tissues, and organs [54].

Proline has also been used for the cryopreservation of some living insects. Kostal et al. [55] added proline to the feed of fruit fly larvae. The proline intake increased the fruit fly larvae survival rate from $0.7 \%$ to $42.1 \%$ when cultured at $-5^{\circ} \mathrm{C}$. It was believed that proline reduced protein unfolding and cell membrane fusion, thus improving the survival rate in cold environments. In another study, Dou et al. [56] fed proline to Camponotus japonicus Mayr (insect) for 5 days. When the insects were cooled to $-26.66^{\circ} \mathrm{C}$, their survival rate was over twice that of the control group. Metabolite analysis showed that the proline content of Camponotus japonicus Mayr was greatly increased, improving its freezing tolerance. These findings provide a theoretical and technical basis for freezing more complex tissues, organs, and even living organisms.

\section{Characterization Methods}

4.1. IRI Activity. IRI activity is an important index for CPAs' performance. The most common method for measuring IRI activity is the splat assay, where a small amount of CPAcontained solution is dropped onto an ultracold glass slide and annealed at $-8^{\circ} \mathrm{C}$ for ice recrystallization. The size of the ice grains can be observed under a polarizing microscope [57]. Another method to detect IRI activity is the sucrose sandwich assay, where the CPA is dissolved in a high concentration sucrose solution, quickly frozen, and annealed at $-6^{\circ} \mathrm{C}$ for a period of time to observe the size of ice grains [58]. The size of ice grains is inversely proportional to the IRI activity [36].
TABLE 3: Cryopreservation of various cells using proline.

\begin{tabular}{lcccc}
\hline $\begin{array}{l}\text { Types of } \\
\text { cells }\end{array}$ & $\begin{array}{c}\text { Optimal } \\
\text { concentration }\end{array}$ & $\begin{array}{c}\text { Viability } \\
(\%)\end{array}$ & $\begin{array}{c}\text { Viability of } \\
\text { control group } \\
(\%)\end{array}$ & Reference \\
\hline $\begin{array}{l}\text { Zea } \\
\text { mays L } \\
\text { cell }\end{array}$ & $10 \% \mathrm{wt}$ & $\sim 80$ & $\sim 0$ & {$[53]$} \\
SRBC & $4 \% \mathrm{wt}$ & 72 & 0 & {$[14]$} \\
GLG-82 & $6 \% \mathrm{wt}$ & $\sim 85$ & $\sim 20$ & {$[14]$} \\
LTP-a-2 & $8 \% \mathrm{wt}$ & $\sim 80$ & $\sim 10$ & {$[14]$} \\
3T3 & $6 \% \mathrm{wt}$ & $\sim 80$ & $\sim 20$ & {$[14]$} \\
SMC & $6 \% \mathrm{wt}$ & $\sim 60$ & $\sim 5$ & {$[14]$} \\
Mouse & $2 \mathrm{~mol} / \mathrm{L}$ & 94.7 & 88.4 & {$[54]$} \\
oocyte & & & & \\
\hline
\end{tabular}

The mean grain size (MGS) and the mean largest grain size (MLGS) are used to quantitatively characterize the IRI activity. MGS is the average area of all ice grains in the sample, and software may be used to automatically identify the MGS [59]. Small MGS indicates a strong IRI activity. MLGS is another indicator of the ice grain size. In early reports, MLGS was considered to be the average area of the ten largest ice grains in the field of view [59]. More recently, MLGS was considered to be the average length of the longest axis of the ten largest ice grains [60]. The IRI activity of PVA and PBS measured by splat assay is shown in Figure 2 (our original data). Measuring MLGS is easier but less precise compared with measuring MGS. These two methods have their own advantages and can be used flexibly in practice.

Ice recrystallization rate is the kinetic information for IRI activity, and it is usually measured by a modified sucrose sandwich assay $[23,28,61]$. The sample was cooled to $-50^{\circ} \mathrm{C}$ and anneal at $-5 \sim-10^{\circ} \mathrm{C}$ for 1 hour to recrystallize. Microscopic photos are taken every 2 minutes to calculate the cubic average radius of the ice grains. The average radius of the cube was plotted against time, where the slope of the fitted straight line is the ice recrystallization rate constant $\left(K_{d}\right)[23,61]$. It is also possible to observe the growth of a single ice crystal and record the change of radius for this ice crystal grain. This method may be more convenient but cause less precise in $K_{d}$ [62]. The ice growth rate measured by the 


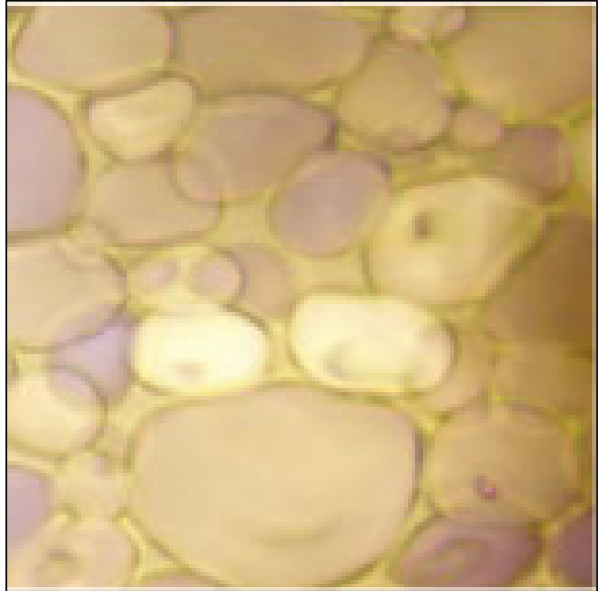

(a)

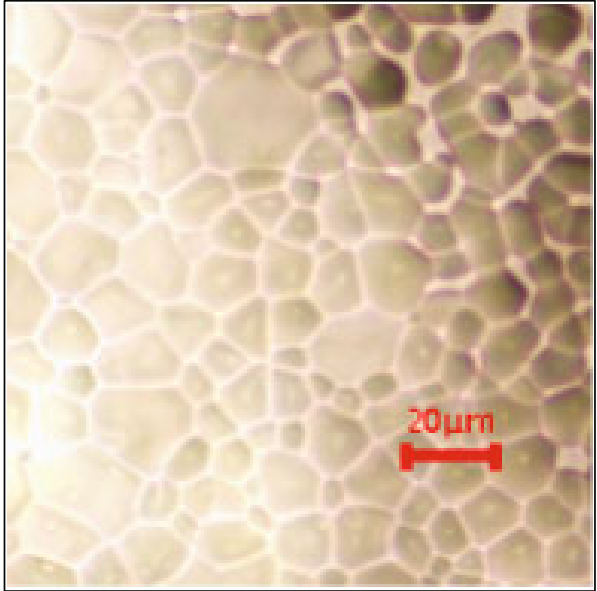

(b)

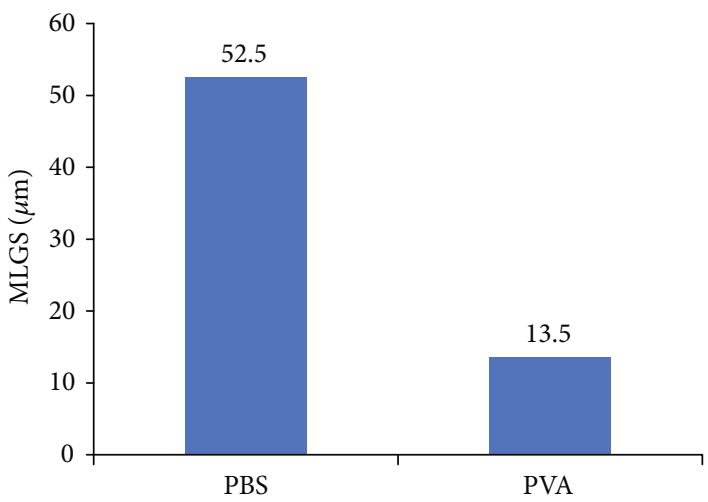

(c)

FIGURE 2: IRI activity measured by splat assay. (a) PBS and (b) $1 \mathrm{mg} / \mathrm{mL}$ PVA dissolved in PBS. (c) The MLGS of PVA and PBS. Ten largest ice grains were chosen, and the lengths of their longest axis were measured to calculate the mean largest grain size (MLGS). MLGS is inversely proportional to IRI activity. Scale bar $=20 \mu \mathrm{m}$ (our original data).

sucrose sandwich assay is shown in Figure 3 (our original data). Generally, a small $K_{d}$ indicates strong IRI activity. The relationship between $K_{d}$ and CPA concentration can be obtained by repeated tests, according to the LWS (Lifshitz-Slyozov-Wagner) theory where the plot of $K_{d}$ over CPA concentration shows an S-shaped curve [61]. $K_{d}$ at the inflection point of the S-shaped curve indicates the critical effective concentration of CPA [28].

Recently, X-ray diffraction (XRD) has been used in the detection of IRI activity [63]. The number of ice orientations is easy to obtain in XRD, and it is inversely proportional to the ice grain size. The kinetic information of ice crystal growth can also be obtained from the graph of the ice crystal orientation change with time. Moreover, the size of ice crystals can be measured in the test tube during freezing and thawing to qualitatively determine the IRI activity [14]. Most macromolecules may show IRI activity when the concentration is high enough. For instance, PEG does not have significant interaction with the ice surface, but it shows obvious IRI activity when its concentration reaches $100 \mathrm{mg} / \mathrm{mL}$ [36].

4.2. Thermal Hysteresis Activity. Thermal hysteresis (TH) is the difference between the melting point and the freezing point. The melting point is the temperature when solid and liquid coexist, whereas the freezing point is the temperature in which the number of ice crystals begins to explosively increase. As mentioned above, it is generally believed that only AFP has TH activity [22]. The classic method of measuring TH activity uses nanoliter osmometry, where the sample is quickly frozen in a nanoliter osmometry instrument and then heated to obtain small ice crystals. Subsequently, the sample is further cooled down at a very slow rate until the explosive growth of ice crystals is observed under the microscope. The temperature difference is $\mathrm{TH}$ for the two processes [12]. However, this method is easily disturbed by some factors, such as the rate of heating and cooling, resulting in poor reproducibility of experimental results [64]. Sonocrystallization can completely measure the cooling, freezing, heating, and melting processes in one test and can test $\mathrm{TH}$ activity by applying ultrasound to start the crystallization process of the AFP solution. This method clearly obtains $\mathrm{TH}$ activity from the curve and has a high reproducibility of experimental results [65]. However, TH obtained by sonocrystallization is different from that obtained by nanoliter osmometry, possibly due to the difference in binding mechanisms of AFP on ice surfaces regarding the ultrasound 


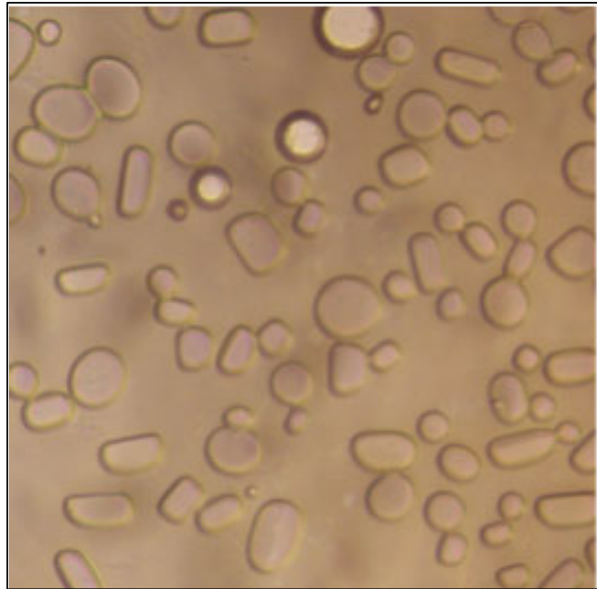

(a)

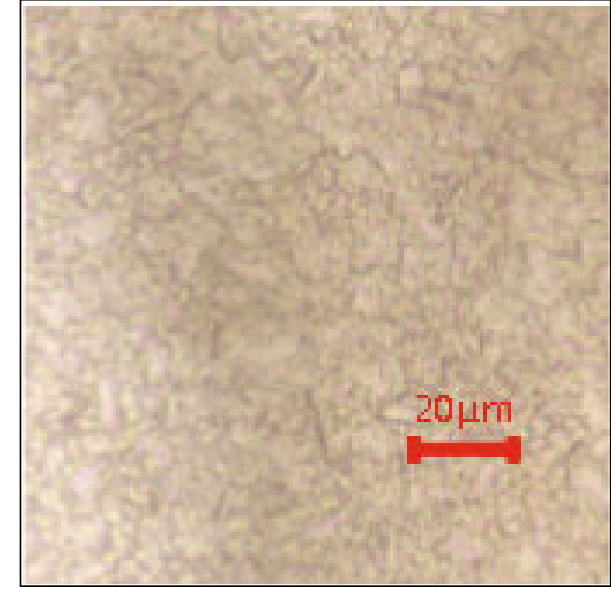

(b)

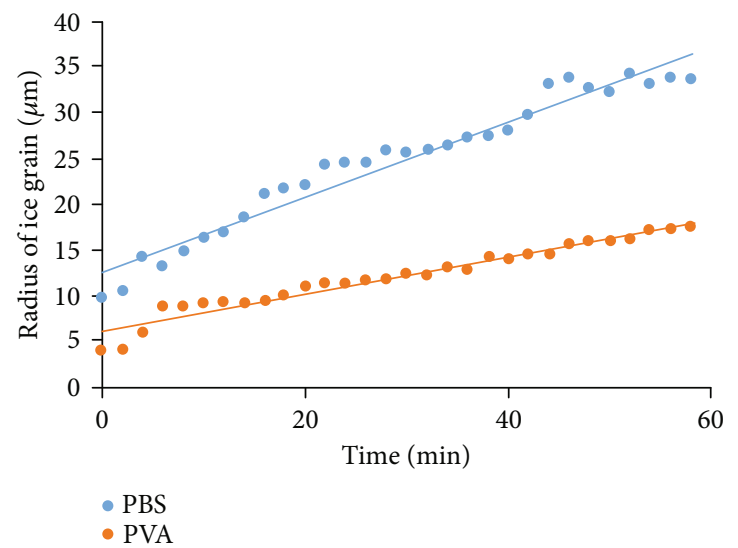

(c)

FIgURE 3: Ice growth rate measured by sucrose sandwich assay. (a) PBS and (b) $1 \mathrm{mg} / \mathrm{mL}$ PVA in PBS. (c) The change in radius of ice grain against time. The slope is the $K_{d}$ which can indicate ice growth rate. Enough sucrose was added to all samples until the mass fraction reached $60 \%$. Scale bar $=20 \mu \mathrm{m}$ (our original data).

treatment [66]. Gold nanoparticle (AuNP) colorimetric method can also test TH activity. This method is simple and highly sensitive. The limit of detection is 100 times higher than traditional methods [67]. DSC is an alternative, stable, and reproducible method to measure $\mathrm{TH}$ activity. The sample can be cooled to $-30^{\circ} \mathrm{C}$ and heated to partially melt, where the recorded temperature $T_{h}$ is the melting point. With the sample being cooled again, the temperature when the ice crystals start to explosively grow is the freezing point $T_{o}$. The difference between $T_{o}$ and $T_{h}$ indicates the TH activity of this CPA. Multiple $T_{h}$ can be obtained for different ice fraction by DSC so that various TH values can be obtained regarding different operating conditions $[68,69]$.

4.3. Cell Activity. In a macrosensor, cells can survive after freezing, and thawing is the key result for choosing CPA in biological cryopreservation. Trypan blue exclusion can detect the survival of postthaw cells, where dead cells are stained while live cells are not. Both recovery and viability can be used to characterize cell survival rates, using the following equations:

$$
\begin{aligned}
& \text { Recovery }=\frac{\text { Unstained cells }}{\text { Total cells before freezing }} \times 100 \%, \\
& \text { Viability }=\frac{\text { Unstained cells }}{\text { Total cells in field of view }} \times 100 \% .
\end{aligned}
$$

In general, postthaw cells show higher viability values than recovery values, as only considering cell viability may overestimate the efficiency of some CPAs [70]. Culturing time also plays an important role in correctly measuring CPAs. The cell densities at zero hour are much higher than after $24 \mathrm{~h}$ culture [71, 72]. Ignoring cell recovery values and culturing time may cause false results of positives.

There are also concerns about whether postthaw cells can maintain their functions. The proliferation of cells can evaluate cell function. The postthaw cells are washed with PBS solution and then cultured in a plate. Under a microscope, the cell proliferation can be observed by counting the number of cells in the well plate for 4 consecutive days. The observed results comprehensively describe the function of postthaw cells, which better indicate the performance of CPAs [14]. 
Cryopreservation of red blood cells is a common method to biologically test CPAs, where the hemolysis rate of red blood cells is used to characterize the ability of CPAs. Typically, red blood cells are cooled with CPA in liquid nitrogen and slowly thawed at room temperature to promote ice recrystallization. After centrifugation, the supernatant is collected and measured for absorbance at $415 \mathrm{~nm}$ with a spectrophotometer. The red blood cells' integrity rate can be calculated according to the absorbance compared with that of the control group [27]. Although cryopreservation of sperms and eggs, stem cells, and other types of cells has also been used to test CPAs, these methods are too complicated for the measurement of CPA performance from a material perspective.

\section{Applications}

5.1. Food. In the food industry, cryopreservation is often used to extend the shelf life of products. The freezing and thawing processes, however, cause irreversible damage to the tissue and cells, affecting the taste and nutrition of foods. Some classic CPAs such as DMSO and PVA are not suitable for food cryopreservation due to their toxicity to humans. At present, most of the CPAs used in food are AFPs. For instance, Du et al. [73] added AFP to mirror carp. After multiple freezethaw cycles, the quality of mirror carp meat was significantly better than that of the control group. Kaleda et al. [23] used AFP to improve the texture and taste (smoother) of ice cream, where the shape of the ice cream relatively remains unchanged during the melting process. Song et al. [4] applied AFP in vegetables such as cucumbers, carrots, and zucchini. The results showed that AFP significantly improved the freshness of these vegetables after thawing. Liu et al. [74] added recombinant carrot antifreeze protein (rCaAFP) to the frozen dough and found that rCaAFP maintained the fermentation capacity and microstructure of the frozen dough during the freeze-thaw cycle, thus improving the taste and texture of the bread. Yeh et al. [75] used recombinant antifreeze protein analogues (rAFP) in meat. The meat showed less drip loss and protein loss and improved juiciness, after freezing and thawing. Calderara et al. [76] found that AFP could shorten the freezing and thawing time of pasta sauce, which is very important for cost-reduction. Kong et al. [77] synthesized antifreeze peptides based on natural AFP. They found that the color, structure, texture, and total anthocyanin and antioxidant content of the cherries treated with antifreeze peptides were retained, and the drip loss was reduced. It is generally concluded that adding AFPs can improve the flavor and quality of frozen foods. But for people with protein allergies, adding AFP to foods may have a potential risk [7].

The taste and freshness of frozen food can be improved for the following reasons [78]. The IRI activity of AFPs can change the size and growth direction of ice crystals, reducing cell membrane damage, water loss, and protein oxidation, Besides, the TH activity of AFPs can lower the freezing point and reduce the growth of ice crystals inside the food, thus avoiding protein denaturation [79].

5.2. Biology and Medicine. Living cells are the key to all kinds of cell-based applications in modern medicine, such as drug development, cell therapy, and tissue engineering [80-82]. Cryopreservation is an effective technique for long-term preservation of various cells. As mentioned above, most CPAs can improve the survival rate of postthaw cells. Some of the CPAs also improve the bioactivity of germ cells. For example, Prathalingam et al. [83] found that AFP orientated frozen cells with ice crystals, resulting in increased sperm osmotic resistance and improving the fertility of bovine sperm. Younis et al. [84] treated Pan troglodytes sperm with antifreeze peptides, where the sperm motility, plasma membrane integrity, and acrosome integrity were significantly increased after thawing.

Cryopreservation of tissues and organs is a higher level for CPAs. The common problems include uneven heating causing thermal stress in the process of rewarming, which breaks the cellular interactions for tissues and organs [85]. Manuchehrabadi et al. [86] used radio frequency-excited mesoporous silica-coated iron oxide nanoparticles to nanowarm porcine arteries previously vitrified in VS55 (a CPA). The nanowarming process made all parts of the tissue be evenly rewarmed. Compared with fresh porcine arteries, the rewarmed porcine arteries had no significant change in the biomechanical properties. Avoiding heterogeneous changes in temperature lays the foundation for cryopreservation of organs and organisms.

Some AFPs are used in cryosurgery which is a minimally invasive surgical technique using a low temperature to destroy bad tissues. When AFP is $10 \mathrm{mg} / \mathrm{L}$, sharp needlelike ice crystals can be produced in cells at low temperatures, destroying cancer cells $[87,88]$. Flounder antifreeze peptide can act as an adjuvant to improve the ablation effect of Copenhagen rats in cryosurgery, which could enhance its efficiency [89]. Additionally, low concentrations of AFP in cryosurgery can reduce cryopreservation complications for viable tissues [90]. These findings may promote the development of cryosurgery and provide new ideas for killing tumour cells.

5.3. Agriculture. Freeze restricts agricultural development in cold conditions, such as in winter, at polar regions or high altitudes. Statistically, the annual loss of agriculture due to freeze exceeds billions of US dollars [91]. Solving the freezing problem can greatly promote the development of agriculture. The genetically modified crops that can express AFP have been cultivated and have shown excellent freeze tolerance. Zhu et al. [92] transferred the spruce budworm (C. fumiferana) AFP (sbwAFP) gene into Arabidopsis and placed them at $-20^{\circ} \mathrm{C}$ for 30 minutes. The result showed that most of the wild-type Arabidopsis died, while the transgenic Arabidopsis showed a higher survival rate. Moreover, the freezing tolerance of AFP-transgenic wheat can be significantly improved, where the wheat can even survive at $-7^{\circ} \mathrm{C}$ [93]. Tobacco that can express sbwAFP also showed strong antifreeze activity [94].

AFP-transgenic animals showed great potential as well. The Macrozoarces americanus AFP gene has been successfully expressed in goldfish. When attacked by low temperature, AFP-transgenic goldfish showed higher cold tolerance [95]. Besides, the AFP gene in salmon can promote the release of a growth hormone, making the transgenic salmon grow much faster than the wild types [96]. These reports show that 
TABLE 4: The activity of different AFP dimers. (The rectangles are AFP and the painted areas indicate IBS).

\begin{tabular}{|c|c|c|c|}
\hline Dimer figures & Connection methods & $\begin{array}{l}\text { Activity (relative to } \\
\text { monomer) }\end{array}$ & $\begin{array}{c}\text { Reasons for increased } \\
\text { activity }\end{array}$ \\
\hline & \multirow[b]{2}{*}{ Side by side with the inactivation of AFP } & 1.2 & Volume increased \\
\hline & & 1.2 & Volume increased \\
\hline & Side by side with active AFP & 2 & Effective IBS doubled \\
\hline
\end{tabular}

AFP-transgenic plants and animals have great application potential in agriculture. However, the current controversy of genetically modified technology hinders the development.

\section{Methods to Enhance CPA's Performance}

6.1. Combine with Other Substance. Combining CPAs with other reagents is a common method to improve cryopreservation performance. Since the adsorption of PVA to ice is reversible [29], there will be a lot of free PVA molecules in the solution, awaiting to be absorbed and show IRI activity. Ishibe et al. [21] found that although PEG in low concentrations had no IRI activity, it could provide a depletion force to adsorb free PVA to ice so as to enhance the activity of PVA. Other CPAs in colloidal form can also use polymers with smaller molecular weight to improve their activity by the depletion force. Highly hydroxylated block copolymer worms have no cryopreservation activity, but they can improve the activity of PVA [60]. When they are used synergistically, red blood cells can be effectively cryopreserved without adding any organic solvents.

Nian et al. [78] used herring antifreeze protein (hAFP) with chitosan magnetic nanoparticles $\left(\mathrm{CS} @ \mathrm{Fe}_{3} \mathrm{O}_{4}\right)$ to treat red sea bream by vacuum impregnation. It could effectively reduce damage during freeze-thaw cycles and prevent protein and lipids from oxidizing. Cai et al. [97] further discovered that carboxymethyl chitosan magnetic nanoparticles (CCMN) combined with AFP had good cryopreservation on the myofibrils of red sea bream and could delay protein oxidation and inhibit the mechanical damage of cell membranes caused by ice crystals. Cheng et al. [98] developed cold-responsive nanocapsules (CR-NCs) as carriers, which could release trehalose into islet $\beta$ cells. In this way, the postthaw islet $\beta$ cells' recovery is more than $85 \%$.

The polycarboxylate can make AFP be more effectively adsorbed to the ice surface, forcing ice to grow only in more curved parts [99]. Thus, polycarboxylate could enhance the $\mathrm{TH}$ activity of AFP, and the number of carboxylates was proportional to the activity. Moreover, the polyhydroxy compounds can form hydrogen bond networks with free water, resulting in decreases in the effective concentration of free water combined with ice [100]. Therefore, polyhydroxy compounds can also effectively enhance the activity of AFP. The enhancement level is positively related to the number of hydroxyls but has no relationship with the location of the hydroxyls and the carbon chain structure.

6.2. Structural Modification of CPAs. Modifying the structure of CPAs significantly affects the material activity. For example, the general AFP enhancers (such as glycerol) lose their effect after modifying the arginine residues on the beetle DAFP-1 by 1,2-cyclohexanedione [101]. When arginine residues are restored by hydroxylamine, these AFP enhancers can work again. This report indicates that arginine residues are important groups on DAFP-1 that interact with enhancers. There are 7 coils composed of amino acids in the $\beta$-helix antifreeze protein (TmAFP) of wild beetles [102]. After removing one coil through structural modification, the TH activity of TmAFP is significantly reduced. When two coils are added to reach a nine-coil AFP, its TH activity doubles and reaches its maximum value. When the number of coils increased over ten, however, the TH activity is relatively reduced possibly due to the incomplete match between the ice-binding sites (IBS) and the ice lattice. As reported by $\mathrm{Xu}$ [103], the rabbit polyclonal antibody can combine with AFP to form an antibody-AFP complex. This complex is 7 or 8 times larger than the AFP alone and can occupy a larger surface area on the ice to increase the activity of AFP. When two AFPs are connected side by side by a peptide linker, the activity of this dimer doubles. However, if the IBS in one AFP is inactivated, the activity of the dimer is only 1.2 times more than the monomer. When two AFPs are connected by a C-terminal disulfide bond, their IBS is opposite to each other, so they cannot be adsorbed on the ice surface at the same time. In this case, the dimer is also 1.2 times more active than the monomer. In conclusion, as shown in Table 4, when two IBS can bind to the ice surface at the same time, the activity can be doubled. Otherwise, the activity of the dimer increases only because of the increase in volume $[104,105]$. 


\section{Conclusion and Prospect}

The cryopreservation techniques have been widely applied in scientific research, medicine, food, and other fields. In order to reduce the damage of freezing, the uses of CPAs are necessary in many cases. There are two kinds of CPAs: permeable and impermeable. Permeable CPAs are mostly small molecules, which can penetrate into cells during the cooling process to reduce cell dehydration, thus protecting cells by reducing osmotic damage. Impermeable CPAs are mostly macromolecules, which do not enter cells but adsorb onto the ice, inhibiting the growth of ice crystals and reducing their mechanical damage to cells. In addition, AFP can lower the freezing point to prevent organisms from freezing at low temperatures. The activity of CPAs can be basically characterized by IRI activity, cell recovery/viability, and TH activity.

Studies on the cryopreservation mechanism of macromolecules such as PVA and GO indicate that the precisely arranged hydroxyl structure is the key to cryopreservation activity. This reminds us that other substances with precise hydroxyl structures can also be used in cryopreservation. Some substances without cryopreservation ability can enhance the activity of CPAs by increasing the dispersion, solubility, and adsorption. Finding existing materials to explore their cryopreservation activity is an important research direction in the near future. Compared to the development of new CPAs, this method requires less work and can achieve good results. Satisfactory results may also be obtained by modifying the structure of CPAs.

At present, there are the following research directions in cryopreservation.

(1) Finding New CPAs. For instance, DMSO is toxic whereas AFP produces needle-like ice crystals. It is a research hotspot in cryopreservation to find CPAs that are cheap and efficient and have no side effects.

(2) Revealing the Mechanisms of CPAs. The interaction between AFP and ice is still controversial, and the mechanism of other CPAs also has not been fully understood. The study of mechanisms can guide the development and application of CPAs.

(3) Expanding the Applications of CPAs. At present, CPAs are mainly used for the cryopreservation of food, cells, and crops. In fact, CPAs can also be applied to other fields that face freezing hazards, such as aircraft turbines, cables, and road icing. There have been some reports, and it may become a research hotspot in the future $[106,107]$.

(4) Improving the Performance of CPAs. As discussed above, combination and structural modification can improve the performance of CPAs. This is an easier way rather than developing new CPAs, and it is possible to achieve better results.

(5) Studying the Cryopreservation of Tissues, Organs, and Living Organisms. Currently, CPAs have been mainly used for cell cryopreservation. For tissues, organs, and even living organisms, the situation is more com- plicated and there are more aspects to consider. In the future, it is believed that organs can be cryopreserved for a long time to solve the problem of transplantation, and cryonics will not only exist in science fiction films.

\section{Data Availability}

All data used to support the findings of this study are included within the article.

\section{Conflicts of Interest}

The authors declare that they have no conflicts of interest.

\section{Acknowledgments}

This work was supported by the National Natural Science Foundation of China (grant number 51374043).

\section{References}

[1] H. E. Tomalty, E. F. Hamilton, A. Hamilton, O. Kukal, T. Allen, and V. K. Walker, "Kidney preservation at subzero temperatures using a novel storage solution and insect icebinding proteins," Cryo Letters, vol. 38, no. 2, pp. 100-107, 2017.

[2] E. Lee and D. Kim, "Effects of astaxanthin on miniature pig sperm cryopreservation," BioMed Research International, vol. 2018, Article ID 6784591, 9 pages, 2018.

[3] R. Fabbri, R. Vicenti, M. Macciocca et al., "Cryopreservation of ovarian tissue in pediatric patients," Obstetrics and Gynecology International, vol. 2012, Article ID 910698, 8 pages, 2012.

[4] D. H. Song, M. Kim, E.-S. Jin et al., "Cryoprotective effect of an antifreeze protein purified from Tenebrio molitor larvae on vegetables," Food Hydrocolloids, vol. 94, pp. 585-591, 2019.

[5] T. L. Bailey, C. Stubbs, K. Murray, R. M. F. Tomás, L. Otten, and M. I. Gibson, "Synthetically scalable poly(ampholyte) which dramatically enhances cellular cryopreservation," Biomacromolecules, vol. 20, no. 8, pp. 3104-3114, 2019.

[6] J. Yang, L. Gao, M. Liu et al., "Advanced biotechnology for cell cryopreservation," Transactions of Tianjin University, vol. 26, pp. 409-423, 2019.

[7] H. Xiang, X. Yang, L. Ke, and Y. Hu, "The properties, biotechnologies, and applications of antifreeze proteins," International Journal of Biological Macromolecules, vol. 153, pp. 661-675, 2020.

[8] A. L. Devries and D. E. Wohlschlag, "Freezing resistance in some Antarctic fishes," Science, vol. 163, no. 3871, pp. 1073-1075, 1969.

[9] J. G. Duman, V. Bennett, T. Sformo, R. Hochstrasser, and B. M. Barnes, "Antifreeze proteins in Alaskan insects and spiders," Journal of Insect Physiology, vol. 50, no. 4, pp. 259-266, 2004.

[10] B. L. Pentelute, Z. P. Gates, V. Tereshko et al., "X-ray structure of snow flea antifreeze protein determined by racemic crystallization of synthetic protein enantiomers," Journal of the American Chemical Society, vol. 130, no. 30, pp. 96959701, 2008. 
[11] Y. Yamashita, N. Nakamura, K. Omiya, J. Nishikawa, H. Kawahara, and H. Obata, "Identification of an antifreeze lipoprotein fromMoraxellasp. of Antarctic origin," Bioscience Biotechnology \& Biochemistry, vol. 66, no. 2, pp. 239-247, 2002.

[12] B. Sharma, D. Sahoo, and R. Deswal, "Single-step purification and characterization of antifreeze proteins from leaf and berry of a freeze-tolerant shrub seabuckthorn (Hippophae rhamnoides)," Journal of Separation Science, vol. 41, no. 20, pp. 3938-3945, 2018.

[13] P. Mazur, J. Farrant, S. P. Leibo, and E. H. Y. Chu, "Survival of hamster tissue culture cells after freezing and thawing: Interactions between protective solutes and cooling and warming rates," Cryobiology, vol. 6, no. 1, pp. 1-9, 1969.

[14] J. Yang, C. Pan, J. Zhang et al., "Exploring the potential of biocompatible osmoprotectants as highly efficient cryoprotectants," ACS Applied Materials \& Interfaces, vol. 9, no. 49, pp. 42516-42524, 2017.

[15] R. C. Deller, M. Vatish, D. A. Mitchell, and M. I. Gibson, "Synthetic polymers enable non-vitreous cellular cryopreservation by reducing ice crystal growth during thawing," Nature Communications, vol. 5, no. 1, article 3244, 2014.

[16] C. Stubbs, T. L. Bailey, K. Murray, and M. I. Gibson, "Polyampholytes as emerging macromolecular cryoprotectants," Biomacromolecules, vol. 21, no. 1, pp. 7-17, 2020.

[17] H. Geng, X. Liu, G. Shi et al., "Graphene oxide restricts growth and recrystallization of ice crystals," Angewandte Chemie-International Editon, vol. 56, no. 4, pp. 997-1001, 2017.

[18] C. I. Biggs, T. L. Bailey, B. Graham, C. Stubbs, A. Fayter, and M. I. Gibson, "Polymer mimics of biomacromolecular antifreezes," Nature Communications, vol. 8, no. 1, article 1546, 2017.

[19] K. Matsumura and S. H. Hyon, "Polyampholytes as low toxic efficient cryoprotective agents with antifreeze protein properties," Biomaterials, vol. 30, no. 27, pp. 4842-4849, 2009.

[20] P. L. Davies, "Ice-binding proteins: a remarkable diversity of structures for stopping and starting ice growth," Trends in Biochemical Sciences, vol. 39, no. 11, pp. 548-555, 2014.

[21] T. Ishibe, T. Congdon, C. Stubbs, M. Hasan, G. C. Sosso, and M. I. Gibson, "Enhancement of macromolecular ice recrystallization inhibition activity by exploiting depletion forces," ACS Macro Letters, vol. 8, no. 8, pp. 1063-1067, 2019.

[22] X. Ding, H. Zhang, H. Chen, L. Wang, H. Qian, and X. Qi, "Extraction, purification and identification of antifreeze proteins from cold acclimated malting barley (Hordeum vulgare L.)," Food Chemistry, vol. 175, pp. 74-81, 2015.

[23] A. Kaleda, R. Tsanev, T. Klesment, R. Vilu, and K. Laos, "Ice cream structure modification by ice-binding proteins," Food Chemistry, vol. 246, pp. 164-171, 2018.

[24] A. Hakim, J. B. Nguyen, K. Basu et al., "Crystal Structure of an Insect Antifreeze Protein and Its Implications for Ice Binding," Journal of Biological Chemistry, vol. 288, no. 17, pp. 12295-12304, 2013.

[25] R. M. F. Tomas, T. L. Bailey, M. Hasan, and M. I. Gibson, "Extracellular antifreeze protein significantly enhances the cryopreservation of cell monolayers," Biomacromolecules, vol. 20, no. 10, pp. 3864-3872, 2019.

[26] S. Liu, W. Wang, E. von Moos et al., "In vitro studies of antifreeze glycoprotein (AFGP) and a C-linked AFGP analogue," Biomacromolecules, vol. 8, no. 5, pp. 1456-1462, 2007.
[27] S. Matsumoto, M. Matsusita, T. Morita et al., "Effects of synthetic antifreeze glycoprotein analogue on islet cell survival and function during cryopreservation," Cryobiology, vol. 52, no. 1, pp. 90-98, 2006.

[28] A. A. Burkey, C. L. Riley, L. K. Wang, T. A. Hatridge, and N. A. Lynd, "Understanding poly(vinyl alcohol)-mediated ice recrystallization inhibition through ice adsorption measurement and pH effects," Biomacromolecules, vol. 19, no. 1, pp. 248-255, 2018.

[29] T. Inada and S.-S. Lu, "Inhibition of recrystallization of ice grains by adsorption of poly(vinyl alcohol) onto ice surfaces," Crystal Growth \& Design, vol. 3, no. 5, pp. 747-752, 2003.

[30] N. S. Vail, C. Stubbs, C. I. Biggs, and M. I. Gibson, "Ultralow dispersity poly(vinyl alcohol) reveals significant dispersity effects on ice recrystallization inhibition activity," ACS Macro Letters, vol. 6, no. 9, pp. 1001-1004, 2017.

[31] D. J. Phillips, T. R. Congdon, and M. I. Gibson, "Activation of ice recrystallization inhibition activity of poly(vinyl alcohol) using a supramolecular trigger," Polymer Chemistry, vol. 7, no. 9, pp. 1701-1704, 2016.

[32] T. R. Congdon, R. Notman, and M. I. Gibson, "Antifreeze (glyco)protein mimetic behavior of poly(vinyl alcohol): detailed structure ice recrystallization inhibition activity study," Biomacromolecules, vol. 14, no. 5, pp. 1578-1586, 2013.

[33] R. C. Deller, T. R. Congdon, M. A. Sahid et al., "Ice recrystallisation inhibition by polyols: comparison of molecular and macromolecular inhibitors and role of hydrophobic units," Biomaterials Science, vol. 1, no. 5, pp. 478-485, 2013.

[34] L. F. Scatena, M. G. Brown, and G. L. Richmond, "Water at hydrophobic surfaces: weak hydrogen bonding and strong orientation effects," Science, vol. 292, no. 5518, pp. 908-912, 2001.

[35] J. Drzymala, Z. Sadowski, L. Holysz, and E. Chibowski, "Ice/water interface: zeta potential, point of zero charge, and hydrophobicity," Journal of Colloid and Interface Science, vol. 220, no. 2, pp. 229-234, 1999.

[36] C. I. Biggs, C. Stubbs, B. Graham, A. E. R. Fayter, M. Hasan, and M. I. Gibson, "Mimicking the ice recrystallization activity of biological antifreezes. When is a new polymer "active"?," Macromolecular Bioscience, vol. 19, no. 7, article 1900082, 2019.

[37] C. Stubbs, K. A. Murray, T. Ishibe, R. T. Mathers, and M. I. Gibson, "Combinatorial biomaterials discovery strategy to identify new macromolecular cryoprotectants," ACS Macro Letters, vol. 9, no. 2, pp. 290-294, 2020.

[38] T. Fujikawa, T. Ando, Y. Gen, S. H. Hyon, and C. Kubota, "Cryopreservation of bovine somatic cells using antifreeze polyamino-acid (carboxylated poly-L-lysine)," Cryobiology, vol. 76, pp. 140-145, 2017.

[39] K. Matsumura, F. Hayashi, T. Nagashima, and S. Hyon, "Long-term cryopreservation of human mesenchymal stem cells using carboxylated poly-l-lysine without the addition of proteins or dimethyl sulfoxide," Journal of Biomaterials Science Polymer Edition, vol. 24, no. 12, pp. 1484-1497, 2013.

[40] K. Nakayama, T. Yamanaka, Y. Tamada, M. Hirabayashi, and S. Hochi, "Supplementary cryoprotective effect of carboxylated $\varepsilon$-poly-l-lysine during vitrification of rat pancreatic islets," Cryobiology, vol. 88, pp. 70-74, 2019.

[41] A. Tariq, M. Ahmad, S. Iqbal et al., "Effect of carboxylated poly l-Lysine as a cryoprotectant on post-thaw quality and 
in vivo fertility of Nili Ravi buffalo (Bubalus bubalis) bull semen," Theriogenology, vol. 144, pp. 8-15, 2020.

[42] K. Matsumura, J. Y. Bae, H. H. Kim, and S. H. Hyon, "Effective vitrification of human induced pluripotent stem cells using carboxylated $\varepsilon$-poly-l-lysine," Cryobiology, vol. 63, no. 2, pp. 76-83, 2011.

[43] R. Rajan, F. Hayashi, T. Nagashima, and K. Matsumura, "Toward a molecular understanding of the mechanism of cryopreservation by polyampholytes: cell membrane interactions and hydrophobicity," Biomacromolecules, vol. 17, no. 5, pp. 1882-1893, 2016.

[44] J. E. Lovelock and M. W. H. Bishop, "Prevention of Freezing Damage to Living Cells by Dimethyl Sulphoxide," Nature, vol. 183, no. 4672, pp. 1394-1395, 1959.

[45] M. J. Ashwood-Smith, "Preservation of mouse bone marrow at $-79^{\circ}$ C. with dimethyl sulphoxide," Nature, vol. 190, no. 4782, pp. 1204-1205, 1961.

[46] P. J. Stiff, A. R. Koester, M. K. Weidner, K. Dvorak, and R. I. Fisher, "Autologous bone marrow transplantation using unfractionated cells cryopreserved in dimethylsulfoxide and hydroxyethyl starch without controlled-rate freezing," Blood, vol. 70, no. 4, pp. 974-978, 1987.

[47] K. Aita, H. Irie, Y. Tanuma et al., "Apoptosis in murine lymphoid organs following intraperitoneal administration of dimethyl sulfoxide (DMSO)," Experimental and Molecular Pathology, vol. 79, no. 3, pp. 265-271, 2005.

[48] J. Liu, H. Yoshikawa, Y. Nakajima, and K. Tasaka, "Involvement of mitochondrial permeability transition and caspase-9 activation in dimethyl sulfoxide-induced apoptosis of EL-4 lymphoma cells," International Immunopharmacology, vol. 1, no. 1, pp. 63-74, 2001.

[49] R. Pal, M. K. Mamidi, A. K. Das, and R. R. Bhonde, "Diverse effects of dimethyl sulfoxide (DMSO) on the differentiation potential of human embryonic stem cells," Archives of Toxicology, vol. 86, no. 4, pp. 651-661, 2012.

[50] S. S. Buchanan, S. A. Gross, J. P. Acker, M. Toner, J. F. Carpenter, and D. W. Pyatt, "Cryopreservation of stem cells using trehalose: evaluation of the method using a human hematopoietic cell line," Stem Cells and Development, vol. 13, no. 3, pp. 295-305, 2004.

[51] B. Graham, T. L. Bailey, J. R. J. Healey, M. Marcellini, and S. Deville, "Polyproline as a minimal antifreeze protein mimic that enhances the cryopreservation of cell monolayers," Angewandte Chemie-International Editon, vol. 56, no. 50, pp. 15941-15944, 2017.

[52] D. Parvanova, A. V. Popova, I. Zaharieva et al., "Low temperature tolerance of tobacco plants transformed to accumulate proline, fructans, or glycine betaine. Variable chlorophyll fluorescence evidence," Photosynthetica, vol. 42, no. 2, pp. 179-185, 2004.

[53] L. A. Withers and P. J. King, "Proline: a novel cryoprotectant for the freeze preservation of cultured cells ofZea maysL," Plant Physiology, vol. 64, no. 5, pp. 675-678, 1979.

[54] L. Zhang, X. Xue, J. Yan et al., "L-proline: a highly effective cryoprotectant for mouse oocyte vitrification," Scientific Reports, vol. 6, no. 1, article 26326, 2016.

[55] V. Kostal, J. Korbelova, R. Poupardin, M. Moos, and P. Simek, "Arginine and proline applied as food additives stimulate high freeze tolerance in larvae ofDrosophila melanogaster," The Journal of Experimental Biology, vol. 219, no. 15 , pp. $2358-2367,2016$.
[56] M. Dou, Y. Li, Z. Sun, L. Li, and W. Rao, "L-proline feeding for augmented freeze tolerance of Camponotus japonicus Mayr," Science Bulletin, vol. 64, no. 23, pp. 1795-1804, 2019.

[57] C. A. Knight, J. Hallett, and A. L. Devries, "Solute effects on ice recrystallization: an assessment technique," Cryobiology, vol. 25, no. 1, pp. 55-60, 1988.

[58] C. A. Stevens, R. Drori, S. Zalis, I. Braslavsky, and P. L. Davies, "Dendrimer-linked antifreeze proteins have superior activity and thermal recovery," Bioconjugate Chemistry, vol. 26, no. 9, pp. 1908-1915, 2015.

[59] J. Jackman, M. Noestheden, D. Moffat, J. P. Pezacki, S. Findlay, and R. N. Ben, "Assessing antifreeze activity of AFGP 8 using domain recognition software," Biochemical and Biophysical Research Communications, vol. 354, no. 2, pp. 340-344, 2007.

[60] D. E. Mitchell, J. R. Lovett, S. P. Armes, and M. I. Gibson, "Combining biomimetic block copolymer worms with an ice-inhibiting polymer for the solvent-free cryopreservation of red blood cells," Angewandte Chemie-International Editon, vol. 55, no. 8, pp. 2801-2804, 2016.

[61] C. Budke, C. Heggemann, M. Koch, N. Sewald, and T. Koop, "Ice recrystallization kinetics in the presence of synthetic antifreeze glycoprotein analogues using the framework of LSW theory," Journal of Physical Chemistry B, vol. 113, no. 9, pp. 2865-2873, 2009.

[62] M. Dou, C. Lu, Z. Sun, and W. Rao, "Natural cryoprotectants combinations of 1-proline and trehalose for red blood cells cryopreservation," Cryobiology, vol. 91, pp. 23-29, 2019.

[63] A. Fayter, S. Huband, and M. I. Gibson, "X-ray diffraction to probe the kinetics of ice recrystallization inhibition," Analyst, vol. 145, no. 10, pp. 3666-3677, 2020.

[64] M. Takamichi, Y. Nishimiya, A. Miura, and S. Tsuda, "Effect of annealing time of an ice crystal on the activity of type III antifreeze protein," FEBS Journal, vol. 274, no. 24, pp. 6469-6476, 2007.

[65] A. Gaede-Koehler, A. Kreider, P. Canfield, M. Kleemeier, and I. Grunwald, "Direct measurement of the thermal hysteresis of antifreeze proteins (AFPs) using sonocrystallization," Analytical Chemistry, vol. 84, no. 23, pp. 1022910235, 2012.

[66] L. L. C. Olijve, K. Meister, A. L. Devries et al., "Blocking rapid ice crystal growth through nonbasal plane adsorption of antifreeze proteins," Proceedings of the National Academy of Sciences of the United States of America, vol. 113, no. 14, pp. 3740-3745, 2016.

[67] J. Park, J. H. Lee, Y. Gwak, H. J. Kim, E. S. Jin, and Y.-P. Kim, "Frozen assembly of gold nanoparticles for rapid analysis of antifreeze protein activity," Biosensors and Bioelectronics, vol. 41, pp. 752-757, 2013.

[68] X. Ding, H. Zhang, W. Liu, L. Wang, H. Qian, and X. Qi, "Extraction of carrot (Daucus carota) antifreeze proteins and evaluation of their effects on frozen white salted noodles," Food and Bioprocess Technology, vol. 7, no. 3, pp. 842-852, 2014.

[69] H. Ramlov, A. L. DeVries, and P. W. F. Wilson, "Antifreeze glycoproteins from the antarctic fish Dissostichus mawsoni studied by differential scanning calorimetry (DSC) in combination with nanolitre osmometry," Cryo Letters, vol. 26, no. 2, pp. 73-84, 2005.

[70] K. A. Murray and M. I. Gibson, "Post-thaw culture and measurement of total cell recovery is crucial in the evaluation of 
new macromolecular cryoprotectants," Biomacromolecules, vol. 21, no. 7, pp. 2864-2873, 2020.

[71] K. Matsumura, K. Kawamoto, M. Takeuchi, S. Yoshimura, D. Tanaka, and S.-H. Hyon, "Cryopreservation of a twodimensional monolayer using a slow vitrification method with polyampholyte to inhibit ice crystal formation," ACS Biomaterials Science \& Engineering, vol. 2, no. 6, pp. 10231029,2016

[72] M. C. D. Sharp, A. Picken, T. J. Morris, C. J. Hewitt, K. Coopman, and N. K. H. Slater, "Amphipathic polymermediated uptake of trehalose for dimethyl sulfoxide-free human cell cryopreservation," Cryobiology, vol. 67, no. 3, pp. 305-311, 2013.

[73] X. Du, P. Chang, J. Tian, B. Kong, F. Sun, and X. Xia, "Effect of ice structuring protein on the quality, thermal stability and oxidation of mirror carp (Cyprinus carpio L.) induced by freeze-thaw cycles," LWT- Food Science and Technology, vol. 124, article 109140, 2020.

[74] M. Liu, Y. Liang, H. Zhang et al., "Production of a recombinant carrot antifreeze protein by Pichia pastoris GS115 and its cryoprotective effects on frozen dough properties and bread quality," LWT- Food Science and Technology, vol. 96, pp. 543-550, 2018.

[75] C.-M. Yeh, B.-Y. Kao, and H.-J. Peng, "Production of a recombinant type 1 antifreeze protein analogue by L. lactis and its applications on frozen meat and frozen dough," Journal of Agricultural and Food Chemistry, vol. 57, no. 14, pp. 6216-6223, 2009.

[76] M. Calderara, F. A. Deorsola, S. Bensaid, D. Fino, N. Russo, and F. Geobaldo, "Role of ice structuring proteins on freezing-thawing cycles of pasta sauces," Journal of Food Science and Technology, vol. 53, no. 12, pp. 4216-4223, 2016.

[77] C. H. Z. Kong, N. Hamid, Q. Ma, J. Lu, B.-G. Wang, and V. Sarojini, "Antifreeze peptide pretreatment minimizes freeze-thaw damage to cherries: an in-depth investigation," LWT- Food Science and Technology, vol. 84, pp. 441-448, 2017.

[78] L. Nian, A. Cao, L. Cai, H. Ji, and S. Liu, "Effect of vacuum impregnation of red sea bream (Pagrosomus major) with herring AFP combined with [email protected $]_{3} \mathrm{O}_{4}$ nanoparticles during freeze-thaw cycles," Food Chemistry, vol. 291, pp. 139-148, 2019.

[79] V. Gaukel, A. Leiter, and W. E. L. Spieß, "Synergism of different fish antifreeze proteins and hydrocolloids on recrystallization inhibition of ice in sucrose solutions," Journal of Food Engineering, vol. 141, pp. 44-50, 2014.

[80] L. A. Marquez-Curtis, A. Janowska-Wieczorek, L. E. McGann, and J. A. W. Elliott, "Mesenchymal stromal cells derived from various tissues: biological, clinical and cryopreservation aspects," Cryobiology, vol. 71, no. 2, pp. 181-197, 2015.

[81] J. Yang, Y. Zhu, T. Xu et al., "The preservation of living cells with biocompatible microparticles," Nanotechnology, vol. 27, no. 26, article 265101, 2016.

[82] J. Yang, C. Pan, X. Sui et al., “The hypothermic preservation of mammalian cells with assembling extracellular-matrixmimetic microparticles," Journal of Materials Chemistry B, vol. 5, no. 8, pp. 1535-1541, 2017.

[83] N. S. Prathalingam, W. V. Holt, S. G. Revell, S. Mirczuk, R. A. Fleck, and P. F. Watson, "Impact of antifreeze proteins and antifreeze glycoproteins on bovine sperm during freezethaw," Theriogenology, vol. 66, no. 8, pp. 1894-1900, 2006.
[84] A. I. Younis, B. Rooks, S. Khan, and K. G. Gould, “The effects of antifreeze peptide III (AFP) and insulin transferrin selenium (ITS) on cryopreservation of chimpanzee (Pan troglodytes) spermatozoa," Journal of Andrology, vol. 19, no. 2, pp. 207-214, 1998.

[85] P. S. Steif, M. C. Palastro, and Y. Rabin, "The effect of temperature gradients on stress development during cryopreservation via vitrification," Cell Preservation and Technology, vol. 5, no. 2, pp. 104-115, 2007.

[86] N. Manuchehrabadi, Z. Gao, J. Zhang et al., "Improved tissue cryopreservation using inductive heating of magnetic nanoparticles," Science Translational Medicine, vol. 9, no. 379, article eaah4586, 2017.

[87] H. Koushafar and B. Rubinsky, "Effect of antifreeze proteins on frozen primary prostatic adenocarcinoma cells," Urology, vol. 49, no. 3, pp. 421-425, 1997.

[88] H. Koushafar, L. Pham, C. Lee, and B. Rubinsky, "Chemical adjuvant cryosurgery with antifreeze proteins," Journal of Surgical Oncology, vol. 66, no. 2, pp. 114-121, 1997.

[89] K. Muldrew, J. Rewcastle, B. J. Donnelly et al., "Flounder Antifreeze Peptides Increase the Efficacy of Cryosurgery," Cryobiology, vol. 42, no. 3, pp. 182-189, 2001.

[90] L. Pham, R. Dahiya, and B. Rubinsky, "An in Vivo Study of Antifreeze Protein Adjuvant Cryosurgery," Cryobiology, vol. 38, no. 2, pp. 169-175, 1999.

[91] J. G. Duman and M. J. Wisniewski, "The use of antifreeze proteins for frost protection in sensitive crop plants," Environmental and Experimental Botany, vol. 106, no. SI, pp. 60-69, 2014.

[92] B. Zhu, A.-S. Xiong, R.-H. Peng et al., "Over-expression of ThpI from Choristoneura fumiferana enhances tolerance to cold in Arabidopsis," Molecular Biology Reports, vol. 37, no. 2, pp. 961-966, 2010.

[93] H. K. Khanna and G. E. Daggard, "Targeted expression of redesigned and codon optimised synthetic gene leads to recrystallisation inhibition and reduced electrolyte leakage in spring wheat at sub-zero temperatures," Plant Cell Reports, vol. 25, no. 12, pp. 1336-1346, 2006.

[94] N. Holmberg, J. Farres, J. E. Bailey, and P. T. Kallio, “Targeted expression of a synthetic codon optimized gene, encoding the spruce budworm antifreeze protein, leads to accumulation of antifreeze activity in the apoplasts of transgenic tobacco," Gene, vol. 275, no. 1, pp. 115-124, 2001.

[95] R. Wang, P. Zhang, Z. Gong, and C. L. Hew, "Expression of the antifreeze protein gene in transgenic goldfish (Carassius auratus) and its implication in cold adaptation," Molecular Marine Biology and Biotechnology, vol. 4, no. 1, pp. 20-26, 1995.

[96] A. L. Van Eenennaam and W. M. Muir, "Transgenic salmon: a final leap to the grocery shelf?," Nature Biotechnology, vol. 29, no. 8, pp. 706-710, 2011.

[97] L. Cai, L. Nian, A. Cao, Y. Zhang, and X. Li, "Effect of carboxymethyl chitosan magnetic nanoparticles plus herring antifreeze protein on conformation and oxidation of myofibrillar protein from red sea bream (Pagrosomus major) after freeze-thaw treatment," Food and Bioprocess Technology, vol. 13, no. 2, pp. 355-366, 2020.

[98] Y. Cheng, Y. Yu, Y. Zhang, G. Zhao, and Y. Zhao, "Coldresponsive nanocapsules enable the sole-cryoprotectanttrehalose cryopreservation of $\beta$ cell-laden hydrogels for diabetes treatment," Small, vol. 15, no. 50, article 1904290, 2019. 
[99] N. Amornwittawat, S. Wang, J. G. Duman, and X. Wen, "Polycarboxylates enhance beetle antifreeze protein activity," Biochimica et Biophysica Acta (BBA) - Proteins and Proteomics, vol. 1784, no. 12, pp. 1942-1948, 2008.

[100] N. Amornwittawat, S. Wang, J. Banatlao et al., "Effects of polyhydroxy compounds on beetle antifreeze protein activity," Biochimica et Biophysica Acta (BBA) - Proteins and Proteomics, vol. 1794, no. 2, pp. 341-346, 2009.

[101] S. Wang, N. Amornwittawat, V. Juwita et al., "Arginine, a key residue for the enhancing ability of an antifreeze protein of the beetle Dendroides canadensis," Biochemistry, vol. 48, no. 40, pp. 9696-9703, 2009.

[102] C. B. Marshall, M. E. Daley, B. D. Sykes, and P. L. Davies, "Enhancing the activity of a $\beta$-helical antifreeze protein by the engineered addition of coils," Biochemistry, vol. 43, no. 37, pp. 11637-11646, 2004.

[103] D. W. Wu, J. G. Duman, and L. Xu, "Enhancement of insect antifreeze protein activity by antibodies," Biochimica et Biophysica Acta (BBA) - Protein Structure and Molecular Enzymology, vol. 1076, no. 3, pp. 416-420, 1991.

[104] J. Baardsnes, M. J. Kuiper, and P. L. Davies, “Antifreeze Protein Dimer:," Journal of Biological Chemistry, vol. 278, no. 40, pp. 38942-38947, 2003.

[105] M. B. Dolev, I. Braslavsky, and P. L. Davies, "Ice-binding proteins and their function," Annual Review of Biochemistry, vol. 85, no. 1, pp. 515-542, 2016.

[106] Y. Gwak, J. Park, M. Kim et al., "Creating anti-icing surfaces via the direct immobilization of antifreeze proteins on aluminum," Scientific Reports, vol. 5, no. 1, article 12019, 2015.

[107] A. P. Esser-Kahn, V. Trang, and M. B. Francis, "Incorporation of antifreeze proteins into polymer coatings using siteselective bioconjugation," Journal of the American Chemical Society, vol. 132, no. 38, pp. 13264-13269, 2010. 